\title{
APROXIMACIÓN METODOLÓGICA AL CONCEPTO DE TERRITORIOS DISCURSIVOS
}

\author{
METHODOLOGICAL APPROACH TO THE CONCEPT \\ OF DISCURSIVE TERRITORIES
}

\author{
Sandra Villanueva Gallardo*
}

\begin{abstract}
El siguiente estudio propone una aproximación metodológica al concepto de territorios discursivos (TD) mediante la comprensión recursiva de las relaciones entre territorio y discurso, posicionándose desde una naturaleza diferente a la desarrollada por el pensamiento occidental moderno. Las técnicas de investigación empleadas se sitúan en el ámbito del análisis hermenéutico del discurso, donde el corpus textual analizado corresponde a los discursos territoriales provenientes desde el pueblo mapuche. Esto último, pues consideramos que los grupos en resistencia territorial son un espacio efectivo de representación de TD por el constante choque epistemológico enfrentado con las concepciones eurocéntricas. A partir de aquello, damos cuenta de la presencia de un tipo de territorio otro operando en los discursos de comunidades identitarias que experimentan la territorialidad desde la memoria colectiva, los sentidos afectivos y las imágenes mentales que los configuran.
\end{abstract}

Palabras claves: Recursividad, territorialidad, identidad, hermenéutica, discurso.

The following study proposes a methodological approach to the concept of discursive territories (TDs) through the recursive understanding of the relations between territory and discourse, positioning itselffrom a different nature to that developed by modern western thought. The research techniques employed are placed in the field of hermeneutic discourse analysis, where the textual corpus analyzed corresponds to the territorial discourses coming from the mapuche people. This last, because we consider that the groups in territorial resistance are an effective space of representation of TDs by the constant epistemological clash confronted with eurocentric conceptions. From that, we realize the presence of a different type of territory operating in the discourses of identity communities that experience the territoriality from the collective memory, the affective senses and the mental images that configure them.

Key words: Recursion, territoriality, identity, hermeneutics, discourse.

\section{Introducción}

Uno de los puntos teóricos de partida de esta investigación surge por medio del tratamiento de la relación entre territorio-discurso, donde vislumbramos un mayor acercamiento a comprender al territorio material circunscrito a un espacio físico, como un lugar hegemónico frente a las concepciones territoriales intangibles. Dentro de este mismo espectro, podemos encontrar la relación binaria, definida por polos opuestos entre el discurso y el territorio, donde un elemento subordina al otro. En cambio, nuestra propuesta territorial alude a una vinculación recursiva (Morin 1996) de ambos aspectos, situándose en un análisis crítico de las trayectorias eurocéntricas territoriales (Villanueva Gallardo 2018).

Con el objetivo de llegar a una aproximación metodológica-conceptual de lo que son los TD, se realizarán los siguientes pasos: (1) breve revisión bibliográfica del concepto de territorio como categoría analítica, para revelar los aspectos invisibilizados por las concepciones territoriales actuales (2) identificar los aspectos no considerados para la emergencia de TD en contextos de conflictos o resistencias territoriales (De la Cadena y Starn 2009), como es el caso del pueblo mapuche, y (3) entregaremos una definición operacional del concepto que proponemos.

\section{El territorio epistemológicamente conocido}

El principal aspecto que los TD diferencian de las definiciones actuales es la procedencia de una naturaleza distinta a la desarrollada por el pensamiento hegemónico eurocéntrico. Nos referimos a la forma de concebir el mundo, que ha sido impuesta por medio de la colonización de los distintos territorios latinoamericanos, proceso que Lander (2000) denomina colonialidad del saber,

* Universidad de Los Lagos, Osorno, Chile. Correo electrónico: svillanuevagallardo@ gmail.com 
la que corresponde a la invisivilización/negación de las diversidades de epistemologías indígenas, feministas, lesbianas, negras, etc. y, por esta razón, la exigencia de superioridad del conocimiento androcéntrico, europeo, heterosexual, de clase alta, considerado como universal. De esta manera, nuestra propuesta considera que la colonialidad del saber también concierne a la comprensión del territorio, como un elemento epistemológico que ha sido colonizado y hegemonizado por las disciplinas eurocéntricas.

Así, el Estado chileno, por ejemplo, revela un tipo de territorio único, singular, donde los elementos materiales y físicos priman frente a lo intangible, como pueden ser la espiritualidad asociada a los ancestros de un determinado lugar, relacionando a este modelo una práctica extractivista (Toledo 2006) de los recursos naturales, donde el ser mapuche no tiene mayor significado, sino más bien se devela como un antecedente de conflicto para las políticas de Estado (Barrientos 2014). Lo anterior se contrapone diametralmente con la territorialidad vivida y sentida por el pueblo mapuche, donde son justamente los elementos invisibles para la racionalidad moderna colonial los que los pueblos originarios colocan en valor y definición del territorio (Quidel 1998, Park 2007).

En este contexto, la visión académico-occidental ha avanzado para incorporar los aspectos inmateriales de los territorios que nos rodean, entre algunos de ellos, los elementos poéticos del espacio (Bachelard 1965), las afectividades territoriales (Tuan 1977), las identidades territoriales (Le Bonniec 2002), los simbolismos y sus apropiaciones (Barabas 2004), los imaginarios territoriales (Ther 2006), todos estos son marcos teóricos o metodológicos que permiten aproximarse a la subjetivación humana y colectiva de los territorios.

Por otra parte, un componente metodológico fundamental de los TD es el sentido afectivo expresado por medio de los discursos territoriales (Villanueva Gallardo 2018). En este punto es preciso señalar una distinción con el abordaje que realiza el enfoque no representacional (Thrift 1996, Vannini 2012), el que busca capturar la realidad mediante la diversidad de formas relacionales (Carvajal 2017) con los diferentes actores humanos y no humanos que interactúan en el ambiente (Latour 2005). En este sentido, si bien las metodologías no representacionales abren un campo sensible para comprender las afectividades (Deleuze 1978), entendidas como un modo de pensamiento abstracto, estas terminan por esquivar el real tratamiento de las emociones y sentimientos de los sujetos de conocimiento presentes en la investigación. Esta distancia nos parece se encuentra asentada en el interés por otorgar un carácter de cientificidad occidental al plano creativo, lo que se demuestra en el empleo de un lenguaje altamente encriptado para dar cuenta de formas distintas de razonamiento y abstracción.

Por lo anterior, consideramos seguía sin pronunciarse una postura recursiva que estableciera la posibilidad de observar las concepciones imaginarias (Bachelard 1965, Durand 1968) del territorio, expresadas por medio de los discursos y los afectos, como construcciones territoriales en sí mismas, con fronteras, paisajes, tiempos, memorias y emociones, sin ser despojadas al ámbito de lo ficticio.

Ante este escenario, queremos destacar, brevemente, algunos elementos teóricos recurrentes en las definiciones territoriales actuales, con el objetivo de revisar cómo se proyecta el territorio desde la academia occidentalizada. Desde estas coordenadas figuran los ámbitos relacionados al poder (Restrepo 2010) donde se vinculan diferentes maneras de apropiaciones por parte de los habitantes que se encuentran en un mismo lugar. En este enfoque encontramos a Geiger, quien sostiene que el territorio "es una extensión terrestre delimitada que incluye una relación de poder o posesión por parte de un individuo o un grupo social" (Geiger 1996 en Rodríguez 2010:6). Al igual que Lopes de Souza, quien sigue la misma línea, estableciendo al territorio como un "espacio determinado y delimitado por y a partir de relaciones de poder, que señala así un límite y que opera sobre un sustrato referencial" (Lopes de Souza 1995:78).

En una definición que incorpora los aspectos intangibles, se ubica la conceptualización de Giménez, quien plantea que:

el territorio sería el resultado de la apropiación y valorización del espacio mediante la representación y el trabajo, una "producción" a partir del espacio inscrita en el campo del poder, por las relaciones que pone en juego, y en cuanto tal se caracterizaría por su valor de cambio y podría representarse metafóricamente como la prisión que nos hemos fabricado para nosotros mismos (Giménez 2000:27). 
Además, el territorio ha sido definido como el contenedor de distintas temporalidades e historicidades, donde se podrían leer e identificar "tiempos geológicos, meteorológicos, hidrológicos, biológicos, sociales, políticos, psicológicos, económicos, cada uno con sus ritmos y sus propias duraciones" (Bozzano 2000:45).

Podemos afirmar que estos autores y otros que refieren al territorio (Santos 1997, Claval 2002, Haesbaert 2004, Ther 2012, Floriani, et al. 2013) convergen en la idea que este no se ajusta a límites físicos, sino a las interacciones sociales que allí se producen. Desde este punto de vista, se manifiesta como una construcción social, lo que supone concebirlo no como "un espacio físico 'objetivamente existente', sino como un conjunto de relaciones sociales que dan origen y a la vez expresan una identidad y un sentido de propósito compartidos por múltiples agentes públicos y privados" (Schejtman y Berdegué 2004:5).

Desde otra perspectiva, Molina hace referencia a los etnoterritorios, definiéndolos como "espacios habitados por los pueblos indígenas, que poseen por característica encontrarse delimitados por hitos geográficos reconocidos socialmente por una o más agrupaciones de una misma etnia o de otra distinta" (Molina 1995 en Llantén 2011:30).

El concepto de etnoterritorios nos remite a identificar los procesos de etnogénesis planteados por Boccara, quien afirma que ciertos pueblos indígenas son el resultado de una dinámica sociohistórica específica, "porque la naturaleza de los métodos empleados por los agentes del Estado colonial produjeron un efecto tanto sobre las estructuras objetivas de las comunidades (su economía y organización sociopolítica) como sobre las estructuras cognitivas de los individuos y colectividades" (Boccara 1998:459).

\section{Territorios en conflicto}

Aun cuando encontramos asertiva la mayoría de los aspectos aquí señalados, la premisa que existen diferentes concepciones territoriales entre una sociedad y otra, y que en lo que respecta, por ejemplo, a los pueblos indígenas, las nociones epistémicas que podrían dar cuenta de una compresión espacial acerca de su entorno han sido negadas e invisibilizadas por el pensamiento hegemónico androcéntrico occidental, siguen siendo el pilar que promueve el trasfondo de esta búsqueda investigativa.
Consideramos que las definiciones revisadas se encuentran refiriendo a aspectos simbólicos relevantes, como son la identidad y las relaciones sociales. No obstante, creemos que las articulaciones que se producen en un determinado territorio, donde las vinculaciones intangibles que se llevan a cabo por comunidades o grupos identitarios son altamente relevantes, quedaban sin una caracterización que los contuvieran íntegramente.

Es en este contexto donde planteamos la posibilidad de elucidar la relación territorio-discurso como un territorio otro que da cuenta de un conocimiento invisibilizado por el logocentrismo y la historiografía tradicional del Occidente moderno, lo que nos habla de una manifestación acopiada y no develada en el saber colectivo que se expresa por medio de discursos territoriales-identitarios, en un vínculo de conciencia de existencia y conformación social.

El territorio, para el pueblo mapuche ${ }^{1}$, no puede ser comprendido desde conceptos relacionados intrínsecamente al poder de propiedad. Si bien existe un entendimiento que se asemeja a un orden jerárquico que va desde el $l o f^{2}$ al $w a l l m a p u^{3}$, estos se encuentran integrados por una lógica contrapuesta al del Estado chileno (Llantén 2011).

Lo recién expuesto implica la existencia de diferencias epistemológicas entre la visión occidental y la cosmovisión mapuche en cuanto al entendimiento del territorio, lo que significa una naturaleza distinta, en que el territorio es parte integrante del ser humano (Quintriqueo y Torres 2013). Este elemento es clave para los TD, pues el origen epistemológico distinto hace eco en la imposibilidad histórica que han tenido los diferentes gobiernos chilenos para reconocer culturalmente a los pueblos originarios y distribuir territorialmente sus recursos en un ambiente de real diálogo y respeto entre culturas (Walsh 2010).

Bajo esta premisa, el/la mapuche no solo se piensa en el territorio como parte fundante de este, sino que también se autointerpreta como un cuerpo/ territorio, viéndose a sí mismo/a como extensión territorial de la naturaleza. Con otras palabras, la corporalidad mapuche es significada bajo un concepto territorial que debe ser protegido y defendido al mismo tiempo.

En este sentido, desde la interpretación hermenéutica (Foucault 1979, Ricoeur 2008, Santos 2010) de los discursos territoriales mapuches ${ }^{4}$, podemos encontrar la presencia de dos lógicas contrapuestas ${ }^{5}$ 
respecto del entendimiento del territorio (Contreras 2000, Geeregat y Fierro 2002, García 2006). En un caso, asociada a políticas y acciones estatales, que no respetan ni entienden la cosmovisión indígena, donde el Estado aparece valorando el pensamiento productivo destinado a generar divisas para un sector económico en particular, basado en la maximización de los recursos; en contraposición a la significación mapuche que asigna a los mismos recursos una valoración económica, social, cultural y espiritual (Milla y Rubilar 2015).

Uno de los ejemplos más paradigmáticos de este choque de cosmovisiones ha sido la puesta en marcha de la industria forestal en Chile, donde las comunidades reclaman por los extensos predios de plantaciones de pino y eucaliptus, los que provocan, entre otras consecuencias, la erosión del suelo, la desaparición de la flora y fauna nativa, disminución de las fuentes hídricas debido a la gran cantidad de agua que consumen este tipo de plantaciones, entre otros deterioros del medio ambiente ${ }^{6}$.

Por todo lo anterior, el territorio es entendido por el/la mapuche como un espacio de vida que contiene ribetes ancestrales vinculados a la memoria, la infancia y la espiritualidad (Bacigalupo 1997, Course 2007). A partir de esta lógica, el territorio se concibe como un lugar propio y heredado, donde se encuentran personas que conforman una comunidad. Un lugar donde están enterrados sus ancestros y donde su identidad es más que las características propias que lo hacen ser una cosa y no otra, es el elemento imprescindible para una ontología que da cuenta de un plano fundamental en el pensamiento mapuche (Del Valle Rojas y Soto 2009).

Un aspecto clave de este proceso es reconocer el vínculo emocional que las comunidades mapuches establecen con su territorio (Skewes et al. 2012), el que no solo es un elemento significativo para esta cultura, como por ejemplo la comunidad de la sangre o küpan o la identidad territorial o tüwun (Tricot 2009), sino que se erige como parte relevante de la metodología que desarrollan los TD por significar un elemento fundamental desvalorizado por la racionalidad moderna y el androcentrismo occidental que relega a las emociones a un plano inferior respecto de los intereses económicos producidos por la lógica capitalista.

Bajo este prisma, es claro que el conflicto territorial mapuche alude a sistemas de comprensiones diferentes, los que se elevan como un desafío de interpretación para un mejor entendimiento de las reales condiciones que están en juego. Por ello nuestro planteamiento teórico aspira a generar puentes que permitan avanzar hacia una comprensión intercultural de los territorios y en este sentido pensamos a los discursos territoriales mapuche como un espacio sociocultural efectivo de representación de TD, pero no por ello el único.

\section{Para la emergencia de territorios discursivos}

Aunque las definiciones territoriales hablen de diversos tamaños e intensidades, las concepciones de fondo son cercanas a lo homogeneizante, debido a que el conocimiento que permitiría otro entendimiento territorial ha sido invisibilizado y producido como inexistente (Santos 2010).

En esta perspectiva, los TD son la expresión de un pensamiento territorial que da cuenta de posibilidades de reconocimiento que Ernst Bloch señalaría con el nombre de todavía no, pues se plantean una categoría que "extrae lo que existe como latencia [...] una posibilidad y una capacidad concretas que ni existen en el vacío, ni están completamente determinadas" (Santos 2010:40), siendo el desafío investigativo materializar el todavía no de los TD en un sí a algo diferente.

Con este propósito en mente, es necesario la realización de un interconocimiento ${ }^{7}$ que no olvide las interdependencias que cruzan los saberes; por tanto, no se trata de negar cualquier concepción territorial previa, sino de ampliarlas a otras posibilidades.

La especificidad que postulamos como fundamental en los TD es la propiedad de realidad condicionante de los discursos territoriales, operando como principios en la determinación de dos características principales: (1) la expresión hologramática y (2) el sentido de identidad territorial que asumen esos discursos.

En virtud de lo anterior, suponemos que los discursos territoriales son una fuente inestimable para la manifestación de lo que una sociedad, comunidad o grupo humano, piensa y siente respecto de su conexión con un territorio. La evidencia es que los TD quedan normalmente ocultos a la conciencia y, por tanto, a la manifestación de ideas de la colectividad, situándose más bien en el ámbito reconocido como imaginario (Bachelard 1965, Durand 1968). Sin embargo, la evidencia es posible de alcanzar mediante una tarea de intelección que proponemos como trabajo hermenéutico (Foucault 1979, Ricoeur 
2008, Santos 2010), porque consideramos que es esta la herramienta metodológica que colabora de mejor forma en la elucidación de aspectos ocultos en el lenguaje, además de situarse como un mecanismo para develar elementos invisibilizados acerca de los territorios (Vergara 2010).

Nuestra propuesta territorial aborda la interpretación hermenéutica desde los principios de una metodología descolonizada (Tuhiwai Smith 2016), por lo que la selección de las herramientas metodológicas se basó en la coherencia de dichos principios que abordan y comprenden a quienes constituyen el foco de investigación no como simples objetos o informantes, sino como lo que verdaderamente son: sujeto/a de conocimiento (Hale 2004, Leyva y Speed 2008, Tuhiwai Smith 2016). Esto se traduce principalmente en que las interpretaciones realizadas no son extracciones de información por medio de entrevistas, sino dependen exclusivamente del trabajo colectivo que se realice con el grupo, comunidad o pueblo, por tanto, en nuestro caso estarán supeditadas a los encuentros reiterados con representantes del pueblo mapuche y de las interpretaciones que posteriormente se realicen.

Uno de los supuestos en que se basa esta investigación es que los territorios discursivos actúan como el lugar desde el cual el discurso territorial llega a ser el que es, a indicar una dirección y explicitar un sentido específico, en cualquiera de las formas institucionalizadas por una colectividad (poesía, religión, política, economía, cultura, etc.) pero sin que esa colectividad tenga plena conciencia o evidencia de este. Por lo anterior, planteamos que los TD se encuentran ligados a la imagen hologramática, condición que proponemos develar desde un trasfondo sociocultural y por medio de la interpretación hermenéutica de los discursos territoriales (Villanueva Gallardo 2018:221).

Del mismo modo, conjeturamos que dicho holograma adquiere un sentido territorial identitario, que estructura a los discursos territoriales, realidad otra que, debido a la heterogeneidad de las culturas, así como las distintas maneras de percibir y enunciar los territorios, conviene ser concebida en sus términos plurales para dar cuenta de la diversidad de posibilidades, incluyendo potenciales TD distintos o contrapuestos, operando en un mismo discurso territorial.

La epistemología en la que se enmarca la definición de TD corresponde a un conocimiento situado (Haraway 1995) y localizado en las epistemologías del sur, en conjunto con las consideraciones metodológicas de la hermenéutica diatópica desarrollada por Boaventura Santos. Además, incorporamos elementos provenientes del pensamiento fronterizo (Anzaldúa 1987) y de la crítica planteada por Edgardo Lander en torno a la colonialidad del saber (Lander 2000).

Este marco teórico se explica a partir del posicionamiento político y lugar de enunciación desde el que se pretende dar cuenta de una alternativa territorial distinta, permitiendo comprender que la racionalidad a la que se apela es también diferente y proveniente desde una perspectiva crítica latinoamericana.

\section{Definición operacional de territorios discursivos}

En virtud de lo anterior, proponemos pensar los TD como realidades imaginarias, aunque no ficticias, latentes en los discursos territoriales de los sujetos sociales y que, fundamentalmente, se manifiestan en hologramas que contienen sentidos de identidad territorial.

Al comprender los TD como realidades imaginarias, estamos señalando, por una parte, que son reales para los sujetos colectivos que se identifican con un territorio específico y, por otra, que el ámbito en que estas realidades se materializan no es del orden de lo tangible, ni de lo conceptual, sino del mundo de lo imaginario en tanto constitutivo de la condición humana. Por tanto, los TD se encuentran en permanente construcción por sujetos sociales, al tiempo que estos son, sociohistóricamente, construidos por ellos. Es claro que esta coconstrucción sociohistórica se realiza, la mayoría de las veces, de manera no consciente, por lo que tampoco opera conscientemente en su discursividad (Villanueva Gallardo 2018:229).

En estas perspectivas, es uno de nuestros planteamientos principales definir los TD como un holograma territorial porque opera en relación con las imágenes mentales vinculadas a la memoria colectiva, las que se encuentran en permanente movimiento y pueden ser captadas mediante la interpretación de los sentidos afectivos que son expresados en los discursos territoriales. Esto quiere decir que las afectividades expresadas por medio de los discursos, ya sean muestras de apego o desapego, desprecio, amor, indiferencia, etc., son 
fundamentales para dar cuenta de aspectos invisibilizados por la racionalidad eurocéntrica. En este punto conviene hacer una especificación: cuando hablamos de discursos territoriales se tiende a pensar en el análisis de relatos ceremoniales o con cierto tono formal, sin embargo, nuestra propuesta alude a discursos territoriales como cualquier expresión discursiva, ya sea de forma oral, escrita o iconográfica, preferentemente realizada de manera espontánea, donde se discursea acerca del territorio, siendo una condicionante para estos efectos que se refiera al territorio considerado como propio.

De esta manera, los TD actúan, metafóricamente, como brújula inmersa en los discursos, entregándoles a los sujetos orientaciones y significados específicos respecto de los lugares a los que refieren. Sin embargo, este no es cualquier espacio físico del cual se ejerce cierta soberanía, sino que es un lugar entendido como propio, en consecuencia, lo que se devela son particularidades identitarias que conforman a los sujetos sociales como pertenecientes a un lugar determinado.

Este holograma territorial es distinto al elaborado por el pensamiento eurocéntrico, principalmente porque su propuesta señala a un territorio que no puede ser pensado al margen del discurso debido a que se constituye en/con el discurso, aun cuando no es creado por este. Con otras palabras, solo pueden manifestarse discursivamente. En ellos podemos encontrar elementos semejantes al territorio convencional, por ejemplo: paisajes, memorias, tiempos, espacios, así como otros factores de identidad territorial: límites y fronteras, sentidos del poder, los que actúan también discursivamente. Esto se logra evidenciar por medio de lo que denominamos líneas de fuga (Guattari 2013) en los discursos, traducidos como aspectos afectivos plasmados en alguna instancia mediante el relato oral, escrito o icónico, como es el caso de las imágenes y sus simbolismos (Rivera Cusicanqui 2015), los que pretendemos rastrear por medio de talleres, entrevistas y encuentros reiterados con los sujetos/sujetas de conocimientos pertenecientes al pueblo mapuche.

Consideramos que tal discursividad puede desplegarse en una interpretación hermenéutica, ya que, al margen de la acción interpretativa, los TD permanecen ocultos, aunque activos en los discursos territoriales. Así, requeriremos de una hermenéutica de los TD que dé cuenta de dichos aspectos invisibilizados por omisión o represión, sean, por ejemplo, emociones o sentimientos ligados a deseos o re-sentimientos vinculados a frustraciones, o bien relaciones de poder reprimidas o desconocidas, además de fronteras territoriales identitarias sentidas como propias o como usurpadas, características que pueden coincidir o contradecir relatos hegemónicos respecto de un territorio en particular.

Dichos aspectos serán indagados por medio de tres características principales que se convertirán en criterios metodológicos: (1) memoria colectiva, traducida a elementos discursivos que contengan aspectos recurrentes y de alta carga significativa respecto del territorio; (2) líneas de fuga, entendidas como marcas afectivas (nostalgia, amor, desprecio, indiferencia, odio, etc.) que indiquen conexión con un determinado lugar (Tuan 1977); (3) mapas mentales del territorio, imágenes que sean plasmadas por los sujetos que definen un territorio en particular.

\section{Consideraciones finales}

A modo de conclusión, este trabajo tuvo por objetivo realizar una aproximación metodológica hacia la emergencia de un tipo de territorio que existe en la memoria e imaginación de los sujetos sociales que habitan o habitaron un determinado lugar. Estos territorios otros son distintos porque responden a una naturaleza localizada en los aspectos intangibles, manifestándose como realidades imaginarias inmersas en hologramas territoriales que adquieren un profundo sentido de identidad.

Asimismo, la zona desde donde es posible acceder a los TD es por medio de los discursos territoriales, siendo el análisis hermenéutico una herramienta metodológica para lograr su elucidación. De este modo, conjeturamos que los discursos territoriales mapuches y las cosmovisiones indígenas en general, son un colectivo representativo de las contradicciones que operan en la comprensión occidental de los territorios, por tanto se erigen como un espacio sociocultural en el que es posible indagar acerca de su existencia y especificidad.

Consideramos que el estudio de los TD resulta un aporte para una compresión intercultural de los territorios (Villanueva Gallardo 2018), porque en ellos es posible decodificar tiempos subjetivos que hablan de un territorio concebido desde un pasado rememorado con las diferentes emociones que aquello puede acarrear. Este pasado puede 
estar concebido desde los recuerdos de la infancia a proyecciones utópicas de lo que a los sujetos les hubiese gustado que fuere. Por otra parte, pueden atraer visiones ideales o no deseadas del futuro, un territorio que camina hacia una transformación imaginaria basada en los deseos o frustraciones colectivas. Finalmente, los TD plantean una realidad territorial temporalmente presente que puede ser el resultado de la combinación de todas o de una de las situaciones pasadas o futuras anteriores.

\section{Agradecimientos}

Investigación financiada por la Corporación Nacional de Ciencia y Tecnología (CONICYT) y por la Dirección de Investigación de la Universidad de Los Lagos con el proyecto FNI/03/2017 "Fundamentos teóricos metodológicos de los territorios discursivos para el estudio de la poesía mapuche del sur de Chile y de los discursos territoriales del Estado, a comienzos del siglo XXI".

\section{Referencias Citadas}

Anzaldúa, G.

1987 Borderlands/La Frontera: The New Mestiza. Spinster/ Aunt Lute. San Francisco.

Bachelard, G.

1965 La poética del espacio. Fondo de Cultura Económica. México.

Bacigalupo, A.

1997 "Las múltiples máscaras de Ngünechen: Las batallas ontológicas y semánticas del ser supremo Mapuche en Chile". Journal of Latin American Lore 20 (1):173-204.

Barabas, A.

2004 "La territorialidad simbólica y los derechos territoriales indígenas: reflexiones para el estado pluriétnico". Alteridades. 27:105-119.

Barrientos, C.

2014 Aproximaciones a la cuestión mapuche en Chile. Una mirada desde la historia y las ciencias sociales. RIL editores. Chile.

Boccara, G.

1998 Guerre et ethnogenése Mapuche dans le Chili colonial. L 'invention du soi L'Harmattan, coll Recherches Ameriques Latines. Paris.

Bozzano, $\mathrm{H}$.

2000 "Territorios Reales, Territorios Pensados, Territorios Posibles. Aportes para una Teoría Territorial del Ambiente". Revista Eure. Buenos Aires.

Carvajal, D.

2017 El estudio de los enfoques no representacionales y la movilidad archipielágica: entre cuerpos, afectos y creaciones. Disponible en http://repositorio.uchile.cl/handle/2250/147214 (Consultado 26 de noviembre 2018).

Claval, P.

2002 "El enfoque cultural y las concepciones geográficas del espacio". Boletín de la AGE. Universidad de Paris. 34:21-39.

Contreras, V.

2000 "Discurso público mapuche: Tópico del Wallmapu". Lengua y literatura mapuche, (9):157-168.

Course, $\mathrm{M}$.

2007 "Death, biography and the Mapuche person". Ethnos, 72 (1):77-101.

De la Cadena, M. y Starn, O.

2009 "Indigeneidad: problemáticas, experiencias y agendas en el nuevo milenio". Tabula Rasa. 10:191-223. Colombia.

Deleuze, G.

1978 Curso sobre Spinoza [En línea]https://es.scribd.com/ document/238207467/Deleuze-Gilles-Curso-Sobre-Spinoza (Consultado 27 de noviembre 2018).

Del Valle Rojas, C. y Soto, E.

2009 "Comunicar la salud en contexto: crítica y praxis educomunicativa”. Tempus Actas de Saúde Coletiva. 1:8-48.

Durand, G.

1968 La imaginación simbólica. Amorrortu editores. Buenos Aires.

Floriani, N.; Ther, F. y Floriani, D.

2013 "Territorialidades alternativas e hibridismos en el mundo rural: resiliencia y reproducción de la sociobiodiversidad en comunidades tradicionales de Brasil y Chile meridionales". Polis. Revista Latinoamericana. 34:74-94.

Foucault, M.

1979 La arqueología del saber. Siglo XXI editores. México.

García, M.

2006 "El discurso poético mapuche y su vinculación con los temas de resistencia cultural". Revista Chilena de Literatura, (68):169-197.

Geeregat, O. y Fierro, J.

2002 "Testimonios poéticos del mestizaje mapuche. Memoria y contramemoria en textos de Elicura Chihuailaf, Leonel Lienlaf, Jaime Huenún y Bernardo Colipán”. Revista Razón y Palabra (26), abril-mayo de 2002.

Giménez, G.

2000 Territorio, Cultura e Identidades. La región sociocultural. Cultura y Región. Universidad Nacional. CES. Bogotá.

Guattari, F.

2013 Líneas de fuga. Buenos Aires. Editorial Cactus.

Haesbaert, R.

2004 O mito da desterrito-rializaçao: do "fim dos territórios á multite-rritiralidade. Bertrand. Brasil.

Hale, Ch.

2004 Reflexiones hacia la práctica de una investigación descolonizada. Ponencia presentada en la Reunión de Investigación Indígena, organizada por CLASPO, La Paz, Bolivia.

Haraway, D.

1995 Ciencia, cyborgs y mujeres. Madrid, Cátedra. Feminismos.

Lander, E.

2000 "Ciencias sociales: saberes coloniales y eurocéntricos", en: Edgardo Lander (comp.), La Colonialidad del 
saber: Eurocentrismo y Ciencias Sociales. Perspectivas Latinoamericanas, CLACSO, Buenos Aires: 4-23.

Latour, B.

2005 Reassembling the social: an introduction to actor-network-theory. Oxford; New York: Oxford University Press.

Le Bonniec, F.

2002 "Las identidades territoriales o cómo hacer historia desde hoy día", en: Morales, R. (comp.). Territorialidad Mapuche en el siglo XX. Temuco, IEI-UFRO, Ediciones Escaparate, Chile: 31-49.

Leyva, X. y Speed, Sh.

2008 "Hacia la investigación descolonizada: nuestra experiencia de co-labor" en Xochitl Leyva, Araceli Burguete y Shannon Speed (Coordinadoras) Gobernar (en) la diversidad: experiencias indígenas desde América Latina. Hacia la investigación de co-labor. México D.F., CIESAS, FLACSO Ecuador y FLACSO Guatemala. 34-59.

Lopes de Souza, M.

1995 "O territorio: sobre espaco e poder, autonomía e desenvolvimento”. En Geografía: Conceitos e Temas. Bertrand, Brasil: 77-116.

Llantén, $\mathrm{S}$.

2011 Territorio mapuche Lleulleuche: naturaleza territorial y conflicto con el estado chileno. Memoria de título para optar al título de Geógrafo. Facultad de Arquitectura y Urbanismo. Escuela de Geografía. Universidad de Chile.

Milla, C. y Rubilar, G.

2015 "Un asimétrico escenario de relaciones. Valoración de dirigentes mapuche acerca de las relaciones interétnicas. Análisis desde un enfoque triangular". Revista Antropologías del Sur 3:31-49.

Morin, E.

1996 Introducción al pensamiento complejo. Gedisa. Barcelona.

Neculman, A.

2009 "Wechekeche pu Wallmapu.del Rol Tradicional al Segmento estudiantil: el caso de los hogares estudiantiles mapuche", en Realidades juveniles en Chile. Colectivo Latinoamericano de Jóvenes. Santiago, Chile: Instituto Nacional de la Juventud. FLACSO-Chile. http://hivhealthclearinghouse.unesco.org/ sites/default/files/resources/santiago_file_4a89d29e87cbc. pdf\#page=143 (Consultado 20 de marzo de 2018).

Park, J.

2007 "Discursos y poética mapuche-huilliche actual: cambio generacional y diferencia territorial". Revista Alpha. 24:139-162.

Quidel, L.

1998 "Conflicto By Pass: Un Ejemplo de Relación Contemporánea entre el Estado Chileno y el Pueblo Mapuche". III Congreso Chileno de Antropología. Colegio de Antropólogos de Chile A. G, Temuco.

Quintriqueo, S. y Torres, H.

2013 "Construcción de Conocimiento Mapuche y su relación con el Conocimiento escolar". Estudios Pedagógicos. 39 (1):199-216.

Restrepo, G.

2010 "Aproximación cultural al concepto del territorio". Revista Perspectiva Geográfica. vol. 3. Universidad Nacional de Colombia.

Ricoeur, $\mathrm{P}$.

2008 Hermenéutica y acción: de la hermenéutica del texto a la hermenéutica de la acción. Prometeo libros. Buenos Aires.
Rivera Cusicanqui, S.

2015 Sociología de la imagen Miradas ch'ixi desde la historia andina. Tinta Limón ediciones. Buenos Aires.

Rodríguez, D.

2010 Territorio y territorialidad. Nueva categoría de análisis y desarrollo didáctico de la Geografía.Uni-pluri/versidad. Universidad de Antioquia. Medellín. https://aprendeenlinea. udea.edu.co/revistas/index.php/unip/article/view/9582 (Consultado 20 de marzo de 2018).

Santos, B.

2010 Refundación del Estado en América Latina. Perspectivas desde una epistemología del Sur. Instituto Internacional de Derecho y Sociedad. Programa Democracia y Transformación Global. Lima.

Santos, M.

1997 Técnica, Espaco, Tempo. Globalizacao e meio técnicocientífico informacional. Hucitec. Sao Paulo.

Schejtman, A. y Berdague, J.

2004 "Desarrollo Territorial Rural. RIMISP Centro Latinoamericano para el Desarrollo Rural", en Debates y Temas Rurales $\mathrm{N}^{\circ}$ 1. Santiago. Chile.

Skewes, J.; Solari, M.; Guerra, D. \& Jalabert, D.

2012 "Los paisajes del agua: naturaleza e identidad en la cuenca del río Valdivia”. Chungara. Revista de Antropología Chilena. 44 (2): 299-312.

Ther, F.

2006 "Complejidad Territorial y Sustentabilidad: Notas para una Epistemología de los Estudios Territoriales". Horizontes Antropológicos. 25:105-115.

Ther, F.

2012 "Antropología del territorio". Polis. Revista de la Universidad Bolivariana. 32:493-510.

Thrift, N.

1996 Spatial Formations. London. Sage.

Toledo, V.

2006 Pueblo mapuche derechos colectivos y territorio: Desafios para la sustentabilidad democrática. LOM Ediciones.

Tricot, T.

2009 "El nuevo movimiento mapuche: hacia la (re)construcción del mundo y país mapuche". Revista de la Universidad Bolivariana. 24:175-196.

Tuan, Y F.

1977 Space and Place: The perspective of experience, University of Minnesota, Minneapolis.

Tuhiwai Smith, L.

2016 A descolonizar las metodologías: Investigación y pueblos indígenas. LOM ediciones.

Vannini, P.

2012 Non-Representational Research Methodologie: Re-envisioning Research [en línea] http://www. academia.edu/5217885/Nonrepresentational_Theory_and_ Methodologies_Re-envisioning_Research (Consultado 26 de noviembre 2018).

Vergara, N.

2010 "Saberes y entornos: notas para una epistemología del territorio". Revista Alpha. 31:163-174.

Villanueva Gallardo, S.

2018 "Fundamentos teóricos epistemológicos de los territorios discursivos". Cinta de Moebio. Revista de Epistemología de Ciencias Sociales. 62:221-230.

Walsh, C.

2010 "Interculturalidad crítica y educación intercultural", en: Construyendo Interculturalidad Crítica (edit.) Viaña, J., Tapia, L. y Walsh, C. 75-96. Bolivia. 


\section{Notas}

1 El pueblo mapuche (gente de la tierra en su lengua, el mapuzüngun) es actualmente la sociedad indígena mayoritaria en Chile (aprox. 1.329 .450 personas, lo que equivale al 83,8\% respecto del total de población nacional, Encuesta de Caracterización Socioeconómica Nacional, CASEN, 2015). Para mayores antecedentes sobre estos datos: http://observatorio.ministeriodesarrollosocial.gob. $\mathrm{cl} /$ casenmultidimensional/casen/docs/CASEN_2015_ Resultados_pueblos_indigenas.pdf).

2 El lof es "el espacio territorial limitado por espacios naturales tales como ríos, montes, bosques y conformado por familias emparentadas, patrilinealmente, poseen un origen y una descendencia común" (Mariman et al., 2006 en Llantén, 2011, p. 18).

3 El wallmapu corresponde a la totalidad del territorio mapuche, tanto en sus aspectos físicos como inmateriales (Neculman, 2009).
4 Esta afirmación está basada en el estudio cualitativo realizado en el 2012 en torno a Imaginarios Territoriales de Poetas Mapuche del sur de Chile, en el contexto de mi tesis de magíster, la que tuvo como objetivo el análisis semiótico-hermenéutico de los discursos orales de un grupo de poetas mapuches.

5 Un ejemplo en que se evidencia ambas cosmovisiones en pugna ha sido el denominado caso Ralco, donde las comunidades pehuenches se negaban a la construcción de una represa hidroeléctrica en el Alto Biobío.

6 Acerca de estas y otras implicancias en: http://olca.cl/oca/ chile/region08/forestales05.htm).

7 El término corresponde a Santos (2010:44), siendo definido por el autor como la posibilidad de "aprender otros conocimientos sin olvidar el propio". 
